\title{
Encefalitozoonosis en un grupo de conejos (Oryctolagus cuniculus) de compañía
}

Laura Adelina Bolaños Aguilar ${ }^{*}$ (1) 0000-0002-4754-8896

Tatiana Sánchez-Sánchez ${ }^{2}$ (1) 0000-0002-5342-4312

Luary Carolina Martínez-Chavarría ${ }^{2}$ D 0000-0003-4911-5178

Liliana Aurora Ramos-Garduño' D 0000-0002-0623-812X Alonso Reyes-Matute ${ }^{2}$ (1) 0000-0002-8689-0627 Ricardo Itzcóatl Maldonado-Reséndiz ${ }^{1}$ D 0000-0002-2909-0607

1. Departamento de Etología, Fauna Silvestre y Animales de Laboratorio, Facultad de Medicina Veterinaria y Zootecnia, Universidad Nacional Autónoma de México. Av. Universidad 3000, Delegación Coyoacán, Ciudad de México, CP. 04510.

2. Departamento de Patología, Facultad de Medicina Veterinaria y Zootecnia. Universidad Nacional Autónoma de México. Av. Universidad 3000. Delegación Coyoacán, Ciudad de México, CP. 04510.

* Autor para correspondencia: Correo electrónico: lau22mvz@gmail.com

Recibido: 2018-08-08 Aceptado: 2018-10-01 Publicado: 2019-05-28 Información y declaraciones adicionales en la página 11

(a) Derechos de autor: Laura Adelina Bolaños Aguilar et al. 2019

acceso abierto $\boldsymbol{\varnothing}$

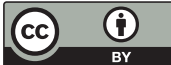

Distribuido bajo una Licencia Creative Commons Atribución 4.0 Internacional (CC-BY 4.0)

\section{Resumen}

Descripción del caso. Dos gazapos en una población de diez conejos de compañía murieron súbitamente y el estudio histopatológico reveló que tenían lesiones compatibles con encefalitozoonosis (uveítis facoclástica, encefalitis piogranulomatosa con esporas y pseudoquistes compatibles con $E$. cuniculi). El resto de la población (ocho conejos) se presentó en el Hospital Veterinario de Especialidades en Fauna Silvestre y Etología Clínica (HVEFSEC) de la Facultad de Medicina Veterinaria y Zootecnia de la UNAM para ser evaluados clínicamente.

Tratamiento y evolución. No hay tratamiento curativo para E. cuniculi y es una zoonosis. En la familia de los propietarios, había dos adultos mayores, personas con mayor riesgo potencial, por lo que se recomendó confinar a la población de conejos de compañía en un lugar aislado y minimizar la exposición. Por razones económicas los propietarios no podían mantener a los conejos en confinamiento, así que se les propuso aplicar la eutanasia a los ocho individuos; ellos estuvieron de acuerdo.

Pruebas de laboratorio. Se realizó el estudio histopatológico que incluyó tinciones de rutina y tinciones especiales. Además, a partir de los bloques de parafina que contenían fragmentos de los órganos con las principales lesiones (cerebro y riñón), se extrajo ADN para realizar la prueba de reacción en cadena de la polimerasa (PCR) anidada. El resultado fue positivo para este microorganismo, ya que se amplificó el fragmento de 549 pb del gen 16S específico de E. cuniculi.

Relevancia clínica. En este artículo se reporta por primera vez la presencia de E. cuniculi en una población de conejos de compañía en México. La prueba confirmatoria es la reacción en cadena de la polimerasa anidada. La encefalitozoonosis es una enfermedad zoonótica, que tiene alta seroprevalencia

Una forma de citar este artículo:

Bolaños-Aguilar LA, Sánchez-Sánchez T, Martínez-Chavarría LC, Ramos-Garduño LA, Reyes-Matute A, Maldonado-Reséndiz RI. Encefalitozoonosis en un grupo de conejos (Oryctolagus cuniculus) de compañía. Clínica Veterinaria: abordaje diagnóstico y terapéutico. 2019;5:e30201951. DOI: 10.22201/fmvz23958766e/201930. 
en las poblaciones de conejos a nivel mundial, sin embargo es una enfermedad altamente subdiagnosticada. El diagnóstico es difícil de realizarse in vivo, sin embargo, se puede realizar la PCR como prueba confirmatoria del patógeno. Es necesario establecer medidas de bioseguridad por su potencial zoonótico, así como seguir generando información epidemiológica para mejorar la sanidad animal y la salud pública.

Palabras clave: Encephalitozoon cuniculi; conejos; Oryctolagus cuniculus; uveítis facoclástica; nefritis intersticial; encefalitis piogranulomatosa; enfermedad emergente; zoonosis.

\section{Encephalitozoonosis in a group of pet rabbits (Oryctolagus cuniculus) Abstract}

Case description. Two young rabbits in a population of ten pet rabbits died suddenly and the histopathological study revealed that they had compatible lesions with encephalitozoonosis (phacoclastic uveitis, pyogranulomatous encephalitis with spores and pseudocysts compatible with E. cuniculi). The rest of the population (eight rabbits) was presented at the Hospital Veterinario de Especialidades en Fauna Silvestre y Etología Clínica (HVE-FSEC) of the Facultad de Medicina Veterinaria y Zootecnia of the UNAM to be evaluated clinically.

Treatment and evolution. There is no curative treatment for E. cuniculi and it is a zoonosis. In the owners' family, there were two older adults, people at higher potential risk, so it was recommended to confine the pet rabbit population to an isolated location and minimize exposure. For economic reasons the owners could not keep the rabbits in confinement, so they were proposed to euthanize the eight individuals; they agreed.

Laboratory tests. The histopathological study was performed which included routine stains and special stains. In addition, from paraffin blocks containing fragments of the organs with the main lesions (brain and kidney), DNA was extracted to perform the nested polymerase chain reaction (PCR). The result was positive for this microorganism, as the $549 \mathrm{pb}$ fragment of the $16 \mathrm{~S}$ gene specific to $E$. cuniculi was amplified.

Clinical relevance. This article reports for the first time the presence of $E$. cuniculi in a population of companion rabbits in Mexico. The confirmatory test is the chain reaction of the nested polymerase. Encephalophozoonosis is a zoonotic disease, which has high seroprevalence in rabbit populations worldwide, but is a highly underdiagnosed disease. The diagnosis is difficult to make in vivo, however, PCR may be performed as a confirmatory pathogen test. It is necessary to establish biosafety measures for their zoonotic potential, as well as to continue generating epidemiological information to improve animal health and public health.

Keywords: Encephalitozoon cuniculi, rabbits, Oryctolagus cuniculus, phacoclastic uveitis, interstitial nephritis, pyogranulomatous encephalitis, zoonosis. 


\section{Descripción del caso}

Se describe el caso de una población de ocho conejos de compañía que fueron llevados al Hospital Veterinario de Especialidades en Fauna Silvestre y Etología Clínica (HVE-FSEC) de la Facultad de Medicina Veterinaria y Zootecnia (FMVZ) de la Universidad Nacional Autónoma de México (UNAM).

Seis meses antes de la consulta, dos conejas que vivían juntas estuvieron en contacto con un macho y se aparearon con él. Una hembra quedó preñada y un mes después nacieron ocho gazapos, que fueron criados por ambas conejas. Tres días después del nacimiento, se encontró un gazapo muerto y no se determinó la causa de la muerte. A los dos meses, un gazapo se deprimió y tenía la cabeza hacia el lado derecho; un médico veterinario zootecnista (MVZ) confirmó la depresión, además de uveítis facoclástica y tortícolis hacia la derecha. El gazapo murió durante el periodo de hospitalización. Se le realizó la necropsia en el Departamento de Patología de la FMVZ de la UNAM, en la que se reportó uveítis facoclástica (heterofílica y granulomatosa) grave generalizada, encefalitis piogranulomatosa grave multifocal y miocarditis piogranulomatosa leve multifocal. Con base en lo anterior, se consideró como diagnóstico presuntivo a Encephalitozoon cuniculi.

Una semana después, las dos conejas adultas y los seis gazapos restantes del grupo antes descrito, fueron referidos por el primer MVZ que los atendió al HVEFSEC para su evaluación clínica.

\section{Hallazgos clínicos}

En el examen físico realizado a las dos conejas adultas y los seis gazapos, no se encontraron signos clínicos relacionados con enfermedad. Sin embargo, se le expuso a los propietarios la probabilidad de que los gazapos y las conejas mostraran signos de enfermedad y muerte súbita posteriormente, tal como había pasado antes con dos de los ocho gazapos hermanos. Además, se les comentó el riesgo zoonótico para la familia, que contaban con adultos mayores en casa. Se les propuso la posibilidad de mantener a los conejos confinados en un lugar con condiciones específicas de sanidad y tratamiento, condición que no podían solventar.

\section{Tratamiento y evolución}

Según la anamnesis y el resultado de histopatología del segundo gazapo que murió, debido al riesgo potencial de zoonosis por E. cuniculi, se propuso a los propietarios aplicar la eutanasia a los ocho ejemplares restantes, ellos estuvieron de acuerdo. Se administró xilacina (3 mg/kg) y ketamina (30 mg/kg) vía intramuscular $y$, una vez que los ejemplares se encontraban en un plano anestésico profundo, se administró pentobarbital $(100 \mathrm{mg} / \mathrm{kg})$ vía intracardiaca. 


\section{Pruebas de laboratorio Estudio post mortem}

Se realizó la necropsia de todos los conejos y se colectaron las muestras en formol amortiguado al $10 \%$ para hacer las pruebas de histopatología convencional. Se tiñeron con hematoxilina y eosina y, algunos tejidos, con las tinciones especiales de histoquímica, Gram y Ziehl Neelsen.

Macroscópicamente, las conejas adultas presentaron múltiples áreas deprimidas sobre la superficie renal que en el estudio microscópico correspondían a focos de nefritis intersticial linfoplasmocítica con ocasionales heterófilos y eosinófilos, así como pequeñas áreas de fibrosis y degeneración tubular. En el resto de los órganos, macroscópicamente no se encontraron cambios relevantes. Sin embargo, en el examen microscópico, los tejidos de ambas conejas presentaron además hepatitis periportal linfoplasmocítica.

En uno de los gazapos se encontró nefromegalia bilateral. Microscópicamente se identificó nefritis tubulointersticial linfoplasmocítica severa generalizada con edema y numerosas esporas y pseudoquistes intratubulares e intersticiales compatibles con E. cuniculi. En encéfalo, estaban afectadas de manera multifocal tanto la corteza como la sustancia blanca del cerebro, se identificó encefalitis granulomatosa severa multifocal con esporas y pseudoquistes compatibles con E. cuniculi intralesionales. En el corazón se observó pancarditis linfoplasmocítica moderada multifocal con miodegeneración moderada, mientras que en hígado se identificaron infiltrados linfoplasmocíticos periportales y degeneración hepatocelular leve generalizada. En el resto de los gazapos, se observaron lesiones congestivas y degenerativas inespecíficas en diferentes órganos (Figura 1).

En el Cuadro 1 se muestran las lesiones microscópicas encontradas en los estudios histopatológicos del segundo gazapo que murió súbitamente (ID 2), así como los gazapos y las conejas que no presentaron signos clínicos de enfermedad (ID $3,4,5,6,7,8,9$ y 10$)$.

\section{Identificación molecular}

A partir de dos bloques de parafina del gazapo 3, que contenían fragmentos de cerebro y riñón, respectivamente, se extrajo ADN empleando el estuche comercial DNeasy blood \& tissue (QIAGEN). Con este ADN se realizó la prueba de reacción en cadena de la polimerasa (PCR) anidada para detectar Encephalitozoon cuniculi, como se ha descrito previamente. ${ }^{1}$ Para esto se realizó una primera reacción de PCR empleando los oligonucleótidos externos P2 (5'- TTG CGG GAT GAG CAG TAG CTG CG -3') y M2 (5'-TGC TGC CAC AAA CAC AAC CCG -3') que amplifican un producto de $1460 \mathrm{pb}$. Posteriormente, $5 \mu \mathrm{L}$ del producto de esta reacción fueron usados como templado para la segunda PCR, empleando los oligonucleótidos Ence_549_forward (5'-ATG AGA AGT GAT GTG TGT GCG -3') y Ence_549_reverse (5'-TCC CAT GCA CTC ACA GGC ATC - $3^{\prime}$ ). El fragmento esperado es de 549 pb y corresponde al gen que codifica la subunidad ribosomal $16 \mathrm{~S}$ de $E$. cuniculi. Ambas reacciones fueron preparadas en un volumen final de $25 \mu \mathrm{L}$ que contenían $12.5 \mu \mathrm{L}$ de TopTaq Master Mix (1.25 unidades de TopTaq DNA polimerasa, buffer de PCR $1 \mathrm{X}$ con $1.5 \mathrm{mM}$ de $\mathrm{MgCl}_{2}$ y $200 \mu \mathrm{M}$ de cada dNTP), $1 \mu \mathrm{L}$ de cada oligonucleótido a una concentración de 25 pm, DNA ( $10 \mu \mathrm{L}$ del ADN extraído para la primera PCR 

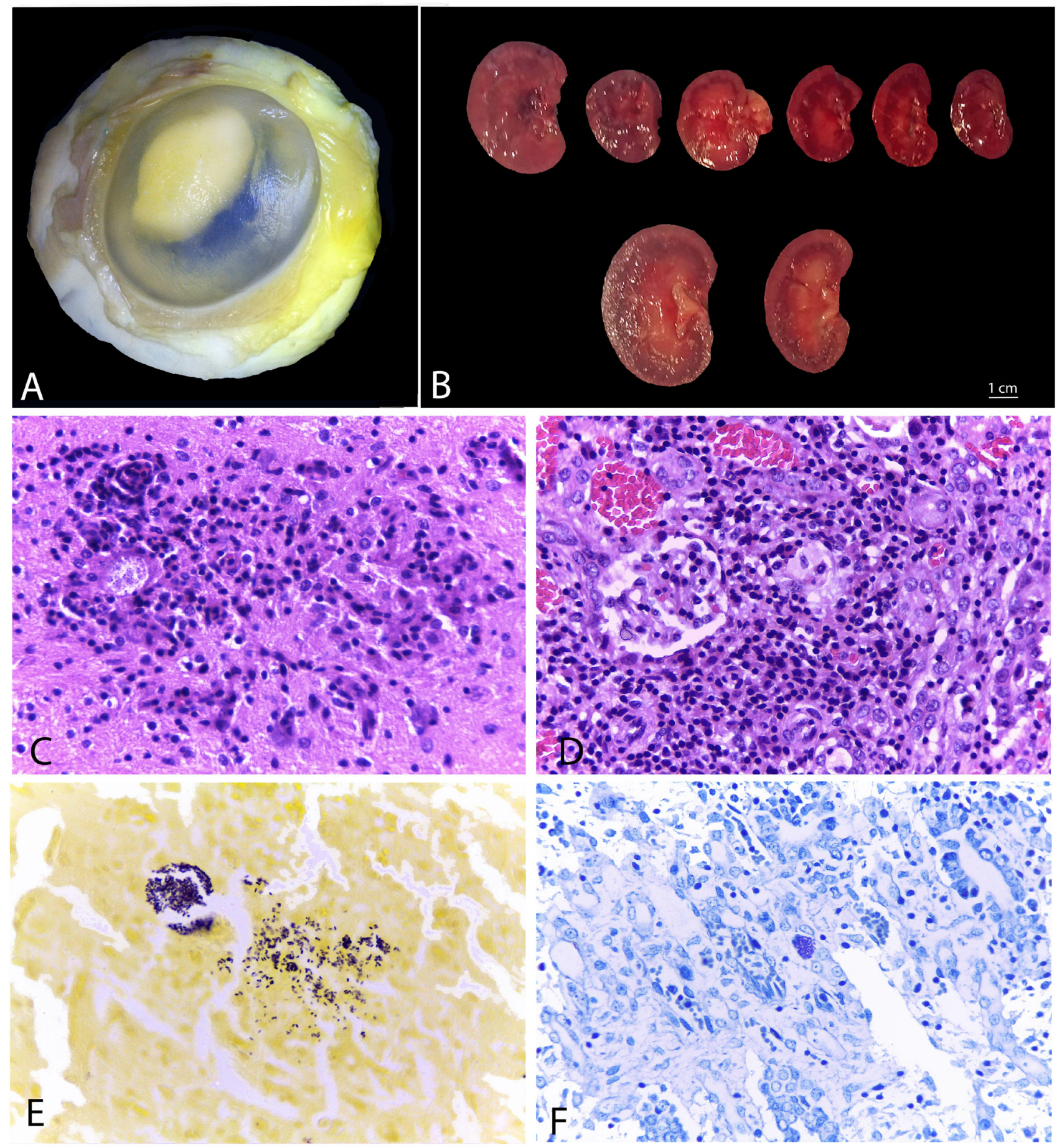

Figura 1. Hallazgos macro y microscópicos encontrados en el examen post mortem. A) globo ocular del gazapo 2 con uveítis, en el que se observa un material blanco-amarillento que ocupa el $60 \%$ de la cámara anterior del ojo. B) cortes mediales de riñones de los gazapos 3 a 8 (superior), y de los adultos 9 y 10 (inferior). En el extremo izquierdo superior, se observa nefromegalia marcada del riñón del gazapo 3 en comparación con sus similares. C) gazapo 3, corte histológico de encéfalo en donde se identifica un foco de infiltrado piogranulomatoso que se dispone rodeando un pseudoquiste con abundantes esporas de E. cuniculi. Tinción H\&E, 40x. D) gazapo 3, corte histológico de riñón en el que se aprecia abundante infiltrado linfoplasmocítico que expande el intersticio. Tinción H\&E, 40x. E) gazapo 3, corte histológico de cerebro en el que se observan abundantes esporas de E. cuniculi gram negativas. Tinción Gram, 100x. F) gazapo 3, corte histológico de riñón en el que se evidencian de color magenta los pseudoquistes de E. cuniculi dentro del epitelio tubular. Tinción Ziehl-Neelsen, 40x. 
Cuadro 1. Resumen de signos clínicos y lesiones histopatológicas por conejo.

\begin{tabular}{|c|c|c|c|}
\hline Conejo & $\begin{array}{l}\text { Fecha de } \\
\text { Muerte }\end{array}$ & Signos clínicos & Lesiones microscópicas \\
\hline $1^{*}$ & $\begin{array}{l}\text { Semana } 1 \\
\text { Muerte } \\
\text { espontánea }\end{array}$ & Muerte súbita & Necropsia no disponible \\
\hline $2^{*}$ & $\begin{array}{l}\text { Semana } 6 \\
\text { Muerte } \\
\text { espontánea }\end{array}$ & $\begin{array}{l}\text { Depresión, uveítis y } \\
\text { tortícolis }\end{array}$ & $\begin{array}{l}\text { I Uveítis facoclástica (heterofilica y granulomatosa) grave } \\
\text { I Encefalitis piogranulomatosa grave y ventriculitis necrosupurativa } \\
\text { grave } \\
\text { I Miocarditis piogranulomatosa leve }\end{array}$ \\
\hline 3 & $\begin{array}{l}\text { Semana } 8 \\
\text { Eutanasia }\end{array}$ & Sin signos clínicos & $\begin{array}{l}\text { I Encefalitis granulomatosa grave con esporas y pseudoquistes de } \\
\text { E. cuniculi intralesionales } \\
\text { I Neuritis linfocítica del nervio óptico } \\
\text { I Nefritis tubulointersticial linfoplasmocítica grave, con numerosas } \\
\text { esporas y pseudoquistes intratubulares e intersticiales compatibles } \\
\text { con E. cuniculi, degeneración y necrosis tubular renal } \\
\text { I Pancarditis linfoplasmocítica con miodegeneración } \\
\text { I Hepatitis periportal linfoplasmocítica heterofilica y degeneración } \\
\text { hepatocelular moderada }\end{array}$ \\
\hline 4 & $\begin{array}{l}\text { Semana } 8 \\
\text { Eutanasia }\end{array}$ & Sin signos clínicos & $\begin{array}{l}\text { I Hepatitis periportal linfoplasmocítica heterofilica, y degeneración } \\
\text { hepatocelular moderadas }\end{array}$ \\
\hline 5 & $\begin{array}{l}\text { Semana } 8 \\
\text { Eutanasia }\end{array}$ & Sin signos clínicos & $\begin{array}{l}\text { I Degeneración hepatocelular moderada } \\
\text { I Degeneración tubular renal moderada }\end{array}$ \\
\hline 6 & $\begin{array}{l}\text { Semana } 8 \\
\text { Eutanasia }\end{array}$ & Sin signos clínicos & I Degeneración hepatocelular leve \\
\hline 7 & $\begin{array}{l}\text { Semana } 8 \\
\text { Eutanasia }\end{array}$ & Sin signos clínicos & I Sin lesiones relevantes \\
\hline 8 & $\begin{array}{l}\text { Semana } 8 \\
\text { Eutanasia }\end{array}$ & Sin signos clínicos & I Sin lesiones relevantes \\
\hline 9 & $\begin{array}{l}\text { Adulto } \\
\text { Eutanasia }\end{array}$ & Sin signos clínicos & $\begin{array}{l}\text { I Nefritis tubulointersticial linfoplasmocítica moderada. Degeneración } \\
\text { tubular renal moderada } \\
\text { I Hepatitis periportal linfoplasmocítica moderada }\end{array}$ \\
\hline 10 & $\begin{array}{l}\text { Adulto } \\
\text { Eutanasia }\end{array}$ & Sin signos clínicos & $\begin{array}{l}\text { I Nefritis tubulointersticial linfoplasmocítica, heterofilica y eosinofilica } \\
\text { moderada. Degeneración tubular renal moderada } \\
\text { I Hepatitis periportal linfoplasmocítica moderada y degeneración } \\
\text { hepatocelular leve }\end{array}$ \\
\hline
\end{tabular}

*Primeros conejos que atendió el MVZ externo a la UNAM 


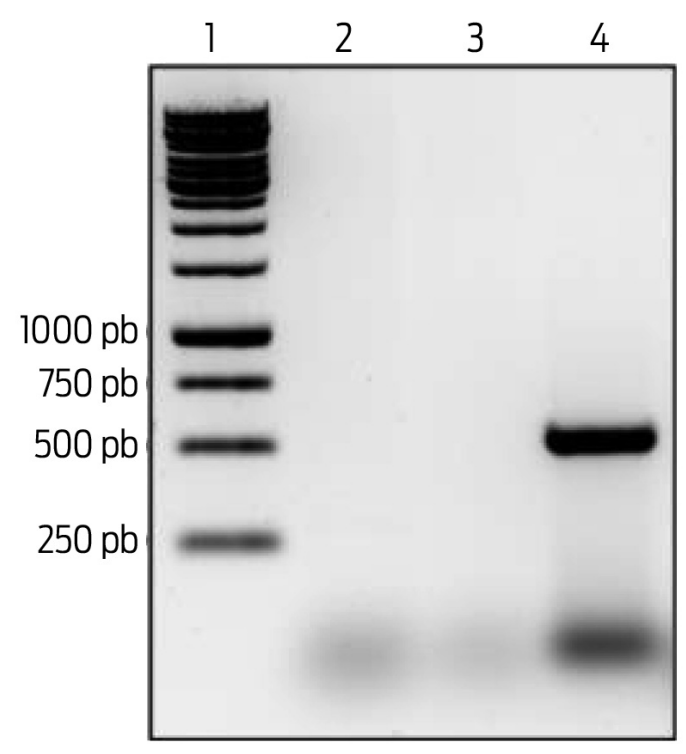

Figura 2. Identificación molecular de E. cuniculi mediante PCR anidada en el gazapo 3. Se muestra el fragmento amplificado de 549 pb. Carril 1: marcador de peso molecular 1Kb; carril 2: control negativo; carril 3: muestra de riñón; carril 4: muestra de cerebro.

y $5 \mu \mathrm{L}$ del producto de la primera reacción para la segunda PCR) y agua grado biología molecular cbp $25 \mu \mathrm{L}$. Cada una de las dos reacciones constó de 35 ciclos. Las condiciones de la primera reacción fueron desnaturalización a $94^{\circ} \mathrm{C}$ por $45 \mathrm{~s}$, alineamiento a $58{ }^{\circ} \mathrm{C}$ por 45 s y extensión a $72{ }^{\circ} \mathrm{C}$ por 2 min. Las condiciones de la segunda PCR fueron desnaturalización a $94^{\circ} \mathrm{C}$ por $30 \mathrm{~s}$, alineamiento a $60^{\circ} \mathrm{C}$ por 45 s y extensión a $72{ }^{\circ} \mathrm{C}$ por un minuto. Los fragmentos de PCR fueron sometidos a electroforesis en un gel de agarosa al $1 \%$ teñido con Syber Safe y posteriormente fueron visualizados con luz ultravioleta.

Como se puede apreciar en la Figura 2, el resultado fue positivo ya que se amplificó el fragmento de 549 pb correspondiente al gen 165 específico de E. cuniculi a partir del ADN extraído de cerebro.

\section{Discusión y relevancia clínica}

Con base en el cuadro clínico del segundo gazapo que murió, los diagnósticos morfológicos obtenidos en la necropsia y los resultados de la PCR, se confirma una infección por Encephalitozoon cuniculi en los casos reportados.

Encephalitozoon cuniculi es un microsporidio de distribución mundial que puede afectar a varias especies de mamíferos incluidos los humanos. Debido a que las enzimas microsporidiales de este patógeno tienen elementos fúngicos como tubulinas y quitina, se ha descrito como un hongo, hecho que varios estudios filogenéticos han corroborado. ${ }^{2}$ E. cuniculi tiene un ciclo de vida directo con transmisión horizontal y vertical (transplacentaria) a través de esporas. ${ }^{3}$ Las esporas son elipsoidales alargadas (2.5-3.2 por 1.2-1.6 $\mu \mathrm{m}$ ) y cuentan con un túbulo polar. ${ }^{4}$

Las principales vías de infección son la ingestión e inhalación de esporas. Experimentalmente, se ha descrito la infección intraperitoneal, intravenosa, intrarrectal, intratraqueal e intracerebral. ${ }^{5}$ La infección por microsporidios aparentemente inicia 
mediante la ingestión de las esporas provenientes de secreciones de mamíferos infectados o indirectamente por consumo de agua contaminada.

Después de la ingestión, las esporas pasan al duodeno en donde el esporoplasma es inoculado en las células del hospedador a través del túbulo polar. Una vez dentro de la célula hospedadora, el esporoplasma se multiplica numerosamente en una vacuola parasitófora. La multiplicación intracelular incluye una fase de divisiones repetidas mediante fisión binaria (merogonia) y una fase que culmina en la formación de esporas (esporogonia). Durante la esporogonia se forma una pared gruesa alrededor de la espora, que proporciona resistencia a las condiciones ambientales adversas. ${ }^{4}$

Una vez que las esporas aumentan en número y colonizan completamente el citoplasma de las células del hospedador, la membrana celular se rompe y libera las esporas a su alrededor. Estas esporas maduras libres pueden infectar nuevas células, provocando la muerte celular, la inflamación local y el daño al DNA celular. ${ }^{4}$ Las esporas se diseminan por el torrente sanguíneo o por el sistema linfático, llegando a establecerse en el cerebro, hígado, riñón y otros órganos. ${ }^{6}$ El microorganismo puede ser excretado por orina y por heces. En el presente caso, las conejas adultas fueron expuestas a un conejo distinto del núcleo familiar, el cual pudo haber sido el causante de la infección.

Se especula que los gazapos contrajeron la infección de manera vertical (transplacentaria). Uno de los gazapos tenía uveítis facoclástica, característica de este agente, porque E. cuniculi rompe la cápsula del cristalino. ${ }^{7}$ En otro gazapo se identificó nefritis tubulointersticial linfoplasmocítica severa generalizada y numerosas esporas y pseudoquistes intratubulares e intersticiales compatibles con E. cuniculi (Figura 1), por ello se puede especular que el agente se estaba eliminando de forma activa a través de la orina.

Künzen et al. (2018) reportan que los signos de conejos infectados incluyen manifestaciones nerviosas en un $75 \%$ de los casos, tales como tortícolis, ataxia, nistagmos, movimientos en círculo, convulsiones, paresis, entre otros. Las manifestaciones oftalmológicas se presentan en $14.6 \%$ de los casos, siendo la uveítis facoclástica la más común. Otras manifestaciones, debido al daño renal son polidipsia, poliuria, inapetencia, pérdida de peso, letargia, deshidratación; estas se presentan en solo un $3.5 \%$ de los casos. ${ }^{3}$

En este caso, el segundo gazapo que murió tuvo depresión, uveítis facoclástica y tortícolis derecha, tres signos que se relacionan directamente con la infección por E. cuniculi. Las conejas adultas y los seis gazapos examinados en consulta no presentaron ninguna manifestación clínica de enfermedad, sin embargo, Maestrini et al. concluyen que un $70 \%$ de los conejos seropositivos que no presentan signos de enfermedad. ${ }^{8}$

El diagnóstico puede realizarse a través de exámenes serológicos como el ensayo por inmunoabsorción ligado a enzima (ELISA), inmunofluorescencia indirecta y carbón inmunoensayo; pero, la evidencia serológica indica exposición, aunque no está relacionada con el grado de parasitosis activa.

En EUA se ha descrito el análisis Western blot para medir los anticuerpos en el suero, ${ }^{9}$ que ha demostrado alta sensibilidad para la detección de IgG e IgM y casi el $100 \%$ de especificidad para estos anticuerpos. Algunos estudios han mostrado que los anticuerpos contra IgM son una herramienta diagnóstica apropiada para 
la determinación de estadios tempranos, porque dichos anticuerpos, declinan a 0 después del día 35 de la infección. ${ }^{10}$

Las esporas se pueden encontrar en orina un mes después de la infección y se excretan en grandes cantidades dos meses después de la infección. Se han identificado anticuerpos lgG en la orina de conejos con infección confirmada, a pesar de ello, los resultados señalan que los anticuerpos solo se detectaron en animales con una fuerte seroreactividad. ${ }^{10}$

La histopatología es una prueba que sugiere fuertemente la infección con microsporidios cuando se evidencia la presencia de la vacuola parasitófora y la reacción inflamatoria adyacente que se genera después de la liberación de las esporas en los tejidos afectados. ${ }^{11}$

Csokai et al. (2009) realizaron un estudio para determinar la distribución y extensión de lesiones histopatológicas en el cerebro y en el riñón en conejos de compañía con y sin signos clínicos de encefalitozoonosis. ${ }^{11}$ En este estudio, encontraron que no hubo correlación entre la severidad de la encefalitis y los signos neurológicos, ya que las lesiones severas fueron encontradas en animales clínicamente sanos. En esta familia de conejos, la mayoría de ellos fue compatible con lesiones histopatológicas en cerebro y riñón, a pesar que no estaban enfermos, excepto los dos gazapos que murieron repentinamente.

Tovar-Rodríguez et al. (2016) reportan la meningoencefalitis granulomatosa no supurativa y la nefritis intersticial crónica con necrosis y descamación del epitelio tubular, como hallazgos histopatológicos comunes en los casos de encefalitozoonosis. ${ }^{12}$ Para el caso que estudiamos, las lesiones más relevantes en la histopatología fueron el infiltrado piogranulomatoso en el encéfalo, y las esporas y pseudoquistes compatibles con E. cuniculi, así como la degeneración y necrosis tubular e infiltrado linfopasmocítico multifocal severo en el riñón, asociado a una nefritis intersticial en uno de los gazapos. Es probable que este gazapo por alguna razón estuviera inmunocomprometido, y que, por esto, expresara estas lesiones, a diferencia de los otros gazapos que solo tenían congestionado el riñón y pulmón, así como degeneración en hígado. Las conejas adultas mostraron infiltrado linfoplasmocítico y degeneración tubular en el riñón, e infiltrado linfoplasmocítico y congestión en el hígado, lesiones típicamente asociadas a E. cuniculi.

La identificación molecular mediante la PCR es la prueba estándar en medicina humana para la detección in vivo de microsporidia. ${ }^{13}$ La PCR del material del cristalino es una herramienta diagnóstica adecuada para uveitis facoclástica en un animal vivo. En muestras de orina, el valor de la detección se ha cuestionado, debido a la excreción intermitente de esporas tanto en conejos con infección clínica como en conejos asintomáticos.

Para este estudio, realizamos la PCR anidada, que confirmó la infección por $E$. cuniculi, al amplificar el fragmento correspondiente al gen $16 \mathrm{~S}$ de este patógeno a partir de muestras de cerebro de uno de los conejos afectados. Estos resultados resaltan la importancia de realizar tanto el análisis histopatológico como la prueba molecular, que asocien las lesiones con la presencia real del patógeno, para llevar a cabo un diagnóstico integral certero, y que permita por tanto, establecer el tratamiento de manera racional y justificada.

Hasta la fecha no hay un tratamiento uniforme establecido en conejos. Éste abarca la inhibición de la proliferación de esporas, una terapia antiinflamatoria y, si es necesario, también una terapia de soporte. ${ }^{9}$ 
Debido a que el microorganismo infecta a los animales inmunocomprometidos, es difícil determinar un método preventivo contra E. cuniculi. Abu Akkada et al. (2016) evaluaron la eficacia de la administración oral (PO), una vez al día (SID) con fenbendazol a $20 \mathrm{mg} / \mathrm{kg}$ y determinaron que es un tratamiento preventivo y curativo en una población de conejos inmunocomprometidos. ${ }^{14}$ En este estudio, se concluye que el fenbendazol es efectivo como tratamiento preventivo, ya que protegió a los conejos contra la infección, cuando se administra antes de la exposición, más no como tratamiento curativo.

Suter et al. (2001) concluyen que en la fase profiláctica de la investigación el tratamiento con fenbendazol es efectivo para controlar la infección, mientras que en la fase curativa, no encontraron evidencia de esporas de $E$. cuniculi en cerebro de los conejos tratados, ${ }^{15}$ sin embargo, el cerebro no es el único órgano blanco que se ve afectado por las esporas del parásito, por lo que no hay evidencia de éste en todos los tejidos. En el caso que aquí estudiamos, debido a que los conejos tenían una infección activa, se especula que el tratamiento con fenbendazol no hubiera tenido efectos curativos; posiblemente solo controlaría la infección. Aunque, no hay evidencia científica que asegure que el fenbendazol reduce o controla la eliminación de esporas.

Por otro lado, ya que los signos no están asociados directamente con el microorganismo, sino con la respuesta inflamatoria desencadentante, es necesario proporcionar medicamentos antiinflamatorios. También se ha descrito el uso de glucocorticoides como la dexametasona y prednisolona, pero su empleo es controversial debido a su posible efecto inmunosupresor. ${ }^{3}$

La administración de antiinflamatorios no esteroidales (AINES), como el meloxicam, también es cuestionable debido a las complicaciones renales que pueden generar. La terapia de soporte se proporciona cuando los signos neurológicos están muy avanzados y los ejemplares dejan de comer, por lo que se les puede proveer una terapia de líquidos, alimentación asistida y un lugar libre de factores estresantes. $^{2}$

En cuanto al potencial zoonótico, E. cuniculi se ha encontrado en humanos inmunocomprometidos y en humanos inmunocompetentes. ${ }^{16}$ Generalmente los signos que genera son diarreas, encefalitis, queratoconjuntivitis, sinusitis, neumonía, miositis, nefritis y hepatitis. ${ }^{17}$ El riesgo de esta zoonosis en México se desconoce. Chilón (2014) reporta que la seroprevalencia en tres criaderos de conejos de compañía de la ciudad de Lima, Perú fue de $56.6 \%,{ }^{18}$ lo que sugiere que la posibilidad de que un conejo esté en contacto con el agente es muy alta, por lo que se traduce en un riesgo potencial para la población humana en contacto con estos conejos.

Las esporas son muy resistentes y llegan a tener un tiempo infectivo de hasta 16 días a $22^{\circ} \mathrm{C}$ y más de 98 días a $4{ }^{\circ} \mathrm{C}$. Para evitar el riesgo zoonótico es necesario no estar en contacto con los animales sospechosos, lavarse las manos después de la manipulación de individuos, y usar guantes y tapabocas. Se ha comprobado la eliminación del parásito mediante el uso de desinfectantes como cuaternarios de amonio, etanol al $70 \%$, formaldehido al $1 \%$ y cloro al $0.1 \% .{ }^{19}$

En la población de conejos de compañía se decidió aplicar la eutanasia debido a que:

Dos individuos de esta población tuvieron muerte súbita y uno de ellos fue diagnosticado con encefalitozoonosis. 
Dentro del núcleo familiar de los propietarios se identificó a dos personas de edad avanzada que podrían tener un mayor riesgo de infección.

Al no tener un tratamiento curativo y al desconocer si la eliminación en orina del parásito es controlada por el fenbendazol, dicho grupo requeriría un manejo sanitario que implicaba el confinamiento de los individuos y el mínimo contacto directo.

Los propietarios se negaron a tener a la población bajo dichas condiciones, ya que no podían evitar tener contacto cercano y no estaban dispuestos a reubicar a los ejemplares.

Los autores no estamos sugiriendo que la eutanasia se deba de indicar en todos los casos de conejos con encefalitozoonosis. Sin embargo, se debe hacer un análisis profundo y específico donde se contemplen conceptos de manejo, terapéutica, convivencia intra- e interespecífica y disponibilidad de recursos.

\section{Financiamiento}

Autofinanciamiento.

\section{Agradecimientos}

Laboratorio de Patología de la FMVZ, en específico a la Dra. Laura Romero Romero y a Jaime Eugenio Córdova López.

\section{Conflictos de interés}

Los autores declaran no tener conflicto de interés.

\section{Contribución de los autores}

LABA, RIMR, LARG: análisis, integración y redacción del caso poblacional. TSS, ARM: revisión de las pruebas de laboratorio, redacción y revisión de imágenes. LCMC: revisión de pruebas de laboratorio, redacción y pruebas moleculares.

\section{Referencias}

1. Csokai J, Joachim A, Gruber A, Künzel F, Ticky A. Diagnostic markers for encephalitozoonosis in pet rabbits. Vet Parasit 2009:163:18-26. doi: 10.1016/j. vetpar.2009.03.057.

2. Thomarat $F$, Vivarès $C P$, Gouy $M$. Phylogenetic analysis of the complete genome sequence of Encephalitzoon cuniculi supports the fungal origen of Microsporidia and reveals a high frequency of fast-evolving genes. J Mol Evol. 2004;59:790. doi: 10.1007/s00239-004-2673-0.

3. Künzel F, Fisher P G. Clinical signs, diagnosis and treatment of Encephalitozoon cuniculi infection in rabbits. Vet Clin Exot Ani. 2018;21:69-82. doi: 10.1016/j. cvex.2017.08.002.

4. Castañón-Olivares LR, Pineda-Murillo J. Microsporidiosis. 2014 (consultado 7 julio 2018) Disponible en: http://www.facmed.unam.mx/deptos/microbiologia/micologia/microsporidiosis.htm

5. Didrer ES, Stovall ME, Green LC, Brindley PJ, Sestak K, Didier OJ. Epidemiology of microsporidiosis: sources and modes of transmission. Vet Parasitol. 2004;126:145-166. doi: 10.1016/j.vetpar.2004.09.006. 
6. Maddox JV, Brooks WM, Solter LF. Bioassays of microsporidia. En: Navon A, Ascher KRS, editores. Bioassays of entomopathogenic microbes and nematodes. New York, NY US: CABI Publishing, 2011.

7. Felchle LM, Sigler RL. Phacoemulsification for the management of Encephalitozoon cuniculi-induced phacoclastic uveitis in a rabbit. Veterinary Ophtalmology. 2002;5(3):211-215. doi: 10.1046/j.1463-5224.2002.00240.x.

8. Maestrini G, Ricci E, Cantile C, Mannella R, Mancianti F, Paci G, D’Ascenzi, Perrucci S. Encephalitozoon cuniculi in rabbits: Serological screening and histopathological findings. Comp immunol Microb Infect Dis 2017;50:54-57. doi: 10.1016/j.cimid.2016.11.012.

9. Desoubeaux G, Patin A, Pesechke R, Joachim A, Cray C. Application of Western blot analysis for the diagnosis of Encephalitozoon cunculi infection in rabbits; example of a quantitative approach. Parasitol Res. 2017;116(2):743-750. doi: 10.1007/s00436-016-5343-4.

10. Furuya $\mathrm{K}$, Asakura $\mathrm{T}$, Igarashi $\mathrm{M}$ et al. Microsporidian Encephalitozoon cuniculi antibodies in rabbit urine samples. Vet Rec. 2009;165(3):85-86. doi: 10.1136/ vetrec. 165.3.85.

11. Csokai J, Gruber A, Künzel F, Ticky A, Joachim A. Encephalitozoonosis in pet rabbits (Oryctolagus cuniculus): pathohistological findings in animals with latent infection versus clinical manifestation. Parasitol Res. 2009;104(3):629-635. doi: 10.1007/s00436-008-1239-2.

12. Rodriguez-Tovar LE, Nevárez-Garza AM, Trejo-Chávez A, et al., Encephalitozoon cuniculi: grading the histological lesions in brain, kidney and liver during primoinfection outbreak in rabbits. J Pathog. 2016:1-9. doi: 10.1155/2016/5768428.

13. Katzwinkel-Wladarsch D, Deplazes $P$, Weber R. Comparison of polymerase chain reaction with light microscopy for detection of microsporidia in clinical specimens. Eur J Clin Microbiol Infect Dis. 1997;16:7-10. doi: 10.1007/ BF01575111.

14. Abu-Akkada SS, Oda SS. Prevention and treatment of Encephalitozoon cuniculi infection in immunosuppressed rabbits with fenbendazole. Iran J Vet Res. 2016;12(2):98-105.

15. Suter C, Müller-Doblies UU, Hatt JM. Prevention and treatment of Encephalitozoon cuniculi infection in rabbits with fenbendazole. Vet Rec. 2001;148:47880. doi: 10.1136/vr.148.15.478.

16. Ozcan O, Ozcan AT., Zafer K. Encephalitozoonosis in New Zealand rabbits and potential transmission risk. Vet parasitol. 201 1;179(1-3):234-7. doi: 10.1016/j. vetpar.2011.02.007.

17. Weber R, Deplazes P, Flepp M, Mathis A, Baumann R, Sauer B, Kuster H, Lüthy R. Cerebral Microsporidiosis due to Encephalitozoon cuniculi in a patient with human immunodeficiency virus infection. N Engl J Med. 1997;336(7):474-478. doi: 10.1056/NEJM 199702133360704.

18. Chilón CVJ. Seroprevalencia de Encephalitozoon cuniculi en conejos destinados como mascotas en la provincia de Lima. (tesis de licenciatura) Perú. Universidad Nacional Mayor de San Marcos; 2014.

19. Waller T. Sensitivity of Encephalitozoon cuniculi to various temperatures, disinfectants, and drugs. Lab Animals. 1979;13:227-230. doi: $10.1258 / 002367779780937753$. 